\title{
QUALIDADE PÓS-COLHEITA DE BANANA 'PRATA' TRATADA POR HIDROTERMIA
}

\author{
Postharvest quality of 'Prata' banana as affected by hot water treatment \\ Claudio de Azevedo Nolasco ${ }^{1}$, Luiz Carlos Chamhum Salomão², Paulo Roberto Cecon ${ }^{3}$, \\ Claudio Horst Bruckner ${ }^{4}$, Aline Rocha ${ }^{1}$
}

\begin{abstract}
RESUMO
As podridões pós-colheita estão entre os maiores problemas da comercialização de bananas e podem ser controladas pela imersão dos frutos em água aquecida. Neste trabalho objetivou-se estudar a influência da hidrotermia na qualidade pós-colheita de banana 'Prata'. Foram testadas as temperaturas de 47, 50, 53 e $56^{\circ} \mathrm{C}$, nos tempos de imersão de 0, 3, 6, 9 e 12 minutos, sendo as avaliações realizadas aos $0,3,6,9$ e 12 dias após os tratamentos. As combinações $56^{\circ} \mathrm{C}$ por 9 e 12 minutos levaram à supressão da ascensão da respiração climatérica dos frutos tratados. Bananas 'Prata' podem ser tratadas em água à temperaturas de $50^{\circ} \mathrm{C}$ por $6 \mathrm{e} 12$ minutos, $53^{\circ} \mathrm{C}$ por 9 minutos e $56^{\circ} \mathrm{C}$ por 3 minutos, sem afetar o seu amadurecimento, e permitindo qualidade pós-colheita adequada.
\end{abstract}

Termos para indexação: Musa spp., tratamento hidrotérmico, amadurecimento, respiração.

\begin{abstract}
Postharvest rots are among the most serious problems for banana commercialization and can be controlled by immersion of the fruits in hot water. The aim of this work was to study the influence of hot water treatments on the postharvest quality of 'Prata' banana. Temperatures of $47,50,53$ and $56^{\circ} \mathrm{C}$ were tested, under immersion for $0,3,6,9$ and 12 minutes, and evaluations carried out after $0,3,6,9$ and 12 days. The combinations $56^{\circ} \mathrm{C}$ for 9 and 12 minutes led to suppression of the respiratory climateric ascension in the treated fruits. 'Prata' banana can be treated in water at temperatures of $50^{\circ} \mathrm{C}$ for 6 and 12 minutes, $53^{\circ} \mathrm{C}$ for 9 minutes and 56 ${ }^{\circ} \mathrm{C}$ for 3 minutes, without affecting its ripening, and allowing appropriate post-harvest quality.
\end{abstract}

Index terms: Musa spp., hot water treatment, ripening, respiration.

(Recebido em 27 de abril de 2006 e aprovado 10 de maio de 2007)

\section{INTRODUÇÃO}

A hidrotermia ou tratamento hidrotérmico é uma técnica cada vez mais utilizada para controle de pragas e doenças em frutos, a exemplo da eliminação de ovos e, ou larvas de mosca-das-frutas e o controle de microrganismos fitopatogênicos (LURIE, 1998).

Por outro lado, o tratamento hidrotérmico pode afetar a qualidade pós-colheita dos produtos hortícolas, causando alterações nos processos do amadurecimento, como produção de etileno, respiração, amolecimento, mudanças na degradação e, ou revelação de pigmentos, além de danos à integridade da membrana plasmática e alterações em componentes do "flavor", a exemplo de sabor, teores de sólidos solúveis, acidez e compostos voláteis. Atenção especial merece também a possibilidade do desenvolvimento de termotolerância (LURIE, 1998; PAULL \& CHEN, 2000).
Acerca de bananas 'Cavendish', Burden (1968) afirmou que o binômio ideal para o controle de Colletotrichum musae era $55^{\circ} \mathrm{C}$ por 2 minutos, antes do amadurecimento dos frutos. Moraes (1999) observou que os tratamentos de bananas 'Prata Anã' a $56^{\circ} \mathrm{C}$ por 6 minutos foi o mais eficiente no controle de podridões in vivo, além de não alterar as características físicas e químicas dos frutos. Por outro lado, $56^{\circ} \mathrm{C}$ por 9 minutos ou mais provocaram escurecimento das extremidades das cascas dos frutos.

Em bananas 'Dwarf Cavendish' e 'Santa Catarina Prata', temperaturas de 50 a $55^{\circ} \mathrm{C}$ por 15 minutos interromperam a hidrólise completa do amido, acarretando maior firmeza dos frutos (DOMINGUES et al., 1998).

Conduziu-se este trabalho, com o objetivo de determinar a influência da hidrotermia na qualidade póscolheita da banana 'Prata'.

\footnotetext{
Engenherio Agrônomo, Mestre - Departamento de Fitotecnia/DFT - Universidade Federal de Viçosa/UFV - Campus Universitário - Viçosa, MG 36570-000 - cnagro@bol.com.br; rochaline@hotmail.com

2Engenheiro Agrônomo, Doutor em Fisiologia Vegetal - Departamento de Fitotecnia/DFT - Universidade Federal de Viçosa/UFV - Campus Universitário Viçosa, MG - 36570-000 - Isalomao@ufv.br - Bolsista do CNPq

${ }^{3}$ Engenheiro Agrônomo, Doutor de Estatística e Experimentação Agronômica - - Departamento de Informática/DPI - Universidade Federal de Viçosa/ UFV - Campus Universitário - Viçosa, MG - 36570-000 - cecon@dpi.ufv.br - Bolsista do CNPq

${ }^{4}$ Engenheiro Agrônomo, Doutor em Genética e Melhoramento - Departamento de Fitotecnia/DFT - Universidade Federal de Viçosa/UFV - Campus

Universitário - Viçosa, MG - 36570-000 - bruckner@ufv.br - Bolsista do CNPq
} 


\section{MATERIAL E MÉTODOS}

Neste trabalho foram utilizados frutos de bananeiras [Musa spp. (AAB)] 'Prata' obtidos em pomar comercial no município de Piau (latitude: $21^{\circ} 30^{\prime} 34^{\prime \prime}$ S; longitude: 43 19 22" W), Minas Gerais, no dia 16/07/2003. O pomar foi conduzido seguindo um sistema de manejo orgânico, apesar de o produtor não apresentar o selo de produto orgânico fornecido por certificadora credenciada junto ao Ministério da Agricultura, Pecuária e Abastecimento.

As pencas, acondicionadas em caixas do tipo "torito", apresentavam frutos na fase pré-climatérica estádio de cor da casca 1, conforme Dadzie \& Orchard (1996) -, com 31 a 35 mm de diâmetro, independentemente da sua posição no cacho, de modo a alterar, o mínimo possível, o sistema de manejo pós-colheita utilizado pelo produtor. Foram utilizadas pencas 'de primeira', segundo o padrão local. Descartaram-se as pencas com os frutos danificados, em início de amadurecimento, deformados e doentes. Os frutos íntegros foram acondicionados em caixas plásticas forradas com papel picado e transportados ao Laboratório de Pós-Colheita da Universidade Federal de Viçosa, onde ocorreu a montagem do experimento, com a subdivisão das pencas em buquês com três frutos cada, que foram lavados em solução de água mais detergente neutro $0,1 \%$ durante cinco minutos a fim de se promover a coagulação do látex e a limpeza superficial dos frutos.

Para o tratamento dos frutos, utilizou-se uma caixa d'água de amianto com capacidade para 250 litros. O sistema de aquecimento da água foi composto de quatro resistências elétricas de 1.500 watts (totalizando 6.000 watts de potência), uma bomba d'água de $1 / 2 \mathrm{cv}$ e um termostato. A temperatura da água foi medida por meio de termômetro digital Gulterm 1200, equipado com ponteira de aço inoxidável com sensor tipo $\mathrm{K}$ (Chromel-Alumel), com precisão de $0,1^{\circ} \mathrm{C}$.

Os buquês foram imersos em água quente seguindo as combinações entre as temperaturas de $47,50,53$ e $56^{\circ} \mathrm{C}$, e os tempos de imersão de $0,3,6,9$ e 12 minutos, com quatro repetições por tratamento.

Depois de tratados, os frutos passaram por uma etapa de resfriamento em água à temperatura de $20 \pm 1,5^{\circ} \mathrm{C}$, por dois minutos, visando a acelerar a recuperação da condição metabólica anterior ao tratamento. Os buquês foram acondicionados em caixas plásticas forradas com papel picado e armazenados em câmaras refrigeradas à temperatura de $20 \pm 1^{\circ} \mathrm{C}$ e umidade de $90 \pm 5 \%$.

Aos $0,3,6,9$ e 12 dias após os tratamentos, foram retiradas amostras ao acaso, para as análises de perda de massa, produção de $\mathrm{CO}_{2}$, temperatura interna do fruto, extravazamento de solutos da casca, consistência e acidez titulável da polpa.

A perda de massa foi obtida pela pesagem dos frutos em cada dia de amostragem, sendo expressa em percentual em relação à massa obtida em cada dia de coleta de dados e a massa encontrada no primeiro dia de avaliação.

A produção de $\mathrm{CO}_{2}$ foi determinada apenas nos frutos tratados a $56^{\circ} \mathrm{C}$ por $0,6,9$ e 12 minutos e resfriados em água à temperatura de $20 \pm 1,5^{\circ} \mathrm{C}$ por dois minutos. Os frutos foram acondicionados em frascos de vidro (1.600 $\mathrm{mL}$ ) hermeticamente fechados. Quarenta minutos após o fechamento dos frascos foram retiradas alíquotas de sua atmosfera que foram injetadas em cromatógrafo a gás, com detector de condutividade térmica, equipado com uma coluna de alumínio preenchida com Porapak Q. As condições de trabalho foram fluxo de $40 \mathrm{~mL}$ por minuto do gás de arraste hélio; corrente elétrica de $150 \mathrm{~mA}$; temperaturas da coluna, do detector e do injetor de 50, 70 e $80^{\circ} \mathrm{C}$, respectivamente; a temperatura ambiente variou de 21 a $27^{\circ} \mathrm{C}$.

Quantificou-se a produção de $\mathrm{CO}_{2}$ dos frutos por meio de comparação entre os picos produzidos pela amostra, no cromatograma, com aqueles produzidos pela injeção de uma alíquota-padrão $\left(6,02 \% \mathrm{~mol}\right.$ de $\mathrm{CO}_{2}$ por mol de mistura $\mathrm{CO}_{2}+\mathrm{N}_{2}$ ). Os resultados foram expressos em $\mathrm{mg} \mathrm{CO} \cdot \mathrm{kg}^{-1} \cdot \mathrm{h}^{-1}$.

O nível de estresse dos frutos tratados termicamente foi avaliado pelo extravasamento de solutos de discos da casca, de acordo com a metodologia descrita por Serek et al. (1995), com adaptações. Retiraram-se da região equatorial dos frutos discos de $1,14 \mathrm{~cm}$ de diâmetro, por meio de um perfurador de rolhas, sendo cada amostra composta constituída por um disco de cada fruto do buquê. Os discos passaram pelas etapas de lavagem com água destilada e secagem superficial em papel absorvente, seguidas de um período de incubação de duas horas em tubo de ensaio contendo $15 \mathrm{~mL}$ de água destilada em condições ambientes. Terminado o tempo de incubação, mediu-se a condutividade elétrica da água com um condutivímetro Schot modelo CG 853. Posteriormente, os tubos de ensaio contendo os discos de casca foram autoclavados $\left(121^{\circ} \mathrm{C}\right.$ a $\left.1,5 \mathrm{~atm}\right)$ por 30 minutos, eliminandose a permeabilidade seletiva das membranas e permitindose o extravasamento total dos solutos celulares. A condutividade elétrica da água foi medida novamente, e os resultados foram expressos como a razão entre a primeira e a segunda medição, multiplicada por 100 .

Para a determinação da consistência da polpa, efetuou-se a retirada de uma porção da casca na região equatorial do fruto. Na polpa exposta, aplicou-se uma força 
(N) até que o tecido não apresentasse mais resistência, por meio de uma ponteira com diâmetro de $12 \mathrm{~mm}$, de um penetrômetro tipo SHIMPO DFS 100 (Digital Force Gauge). Os resultados foram expressos em $\mathrm{kPa}$.

Uma amostra composta da região equatorial da polpa dos três frutos de cada buquê, de peso de aproximadamente 5,0 $\mathrm{g}$ foi retirada para a determinação da acidez titulável. A amostra foi acondicionada em papelalumínio, congelada em nitrogênio líquido e armazenada em "freezer" a $-20^{\circ} \mathrm{C}$ até o momento das determinações. A amostra foi triturada em homogeneizador de tecidos (Politron), juntamente com $50 \mathrm{~mL}$ de água destilada, e posteriormente transferida para erlenmeyer, completandose o volume para $100 \mathrm{~mL}$ com água destilada. A titulação fez-se com solução de $\mathrm{NaOH} 0,05 \mathrm{~N}$, previamente padronizada com biftalato de potássio mais três gotas de indicador fenolftaleína $1 \%$. Os resultados foram expressos em g de ácido málico por $100 \mathrm{~g}$ de polpa.

No dia 07/10/2003 foram adquiridos novos frutos, provenientes do pomar da Universidade Federal de Viçosa, para a determinação da temperatura interna do fruto durante o tratamento hidrotérmico. Utilizou-se um tanque metálico com capacidade para $65 \mathrm{~L}$ de água, isolado internamente com lã-de-vidro. O aquecimento foi efetuado por uma resistência elétrica de $1.000 \mathrm{~W}$ controlada por um termostato.

Realizou-se o monitoramento das temperaturas do ambiente, da água de tratamento e do interior dos frutos por meio de sensores termoelétricos tipo " $\mathrm{T}$ " (hipodérmicos) ligados a um sistema de aquisição de dados MINMAX S210RA. O sistema de aquisição de dados foi acoplado a um microcomputador, no qual as temperaturas foram registradas e armazenadas em intervalos de tempo regulares de um minuto. Os termopares foram inseridos na porção equatorial dos frutos, na região central da polpa. Foram registradas as temperaturas a cada minuto durante o período de imersão em água quente e, sequencialmente, durante o período de resfriamento em água $20 \pm 1{ }^{\circ} \mathrm{C}$ até a temperatura da polpa equilibrar-se com a da água.

Os tratamentos foram distribuídos em parcelas subdivididas, tendo nas parcelas um esquema fatorial de 4 x 5 (quatro temperaturas e cinco tempos de imersão) e, nas subparcelas, as épocas de avaliação, no delineamento inteiramente ao acaso, com quatro repetições. Para a análise dos dados foi adotada a técnica de superfície de resposta, sendo os modelos escolhidos baseados na significância dos coeficientes de regressão, utilizando-se o teste " $t$ " (Student) a $1 \%$ de probabilidade, no coeficiente de determinação e no potencial para explicar o fenômeno biológico. Para a variável produção de $\mathrm{CO}_{2}$, utilizou-se a estatística descritiva.

\section{RESULTADOS E DISCUSSÃO}

A variável perda de matéria fresca apresentou comportamentos quadrático em função do tempo de imersão (TI), com um máximo próximo ao sexto dia após o tratamento, e linear para época de avaliação (EP) (Figura 1).

Mesmo em ambiente controlado $\left(20 \pm 1^{\circ} \mathrm{C}\right.$ e umidade de $90 \pm 5 \%$ ), as perdas médias de matéria fresca dos frutos aos $0,3,6,9$ e 12 dias após o tratamento foram de $0 ; 1,71$; 3,$56 ; 5,40 ;$ e 7,24\%, respectivamente. A perda acumulada no último dia de coleta de dados se aproxima da encontrada por Salomão (1995) em bananas 'Mysore', que apresentaram perda de peso máxima próxima de $6 \%$, decorridos 15 dias após a colheita.

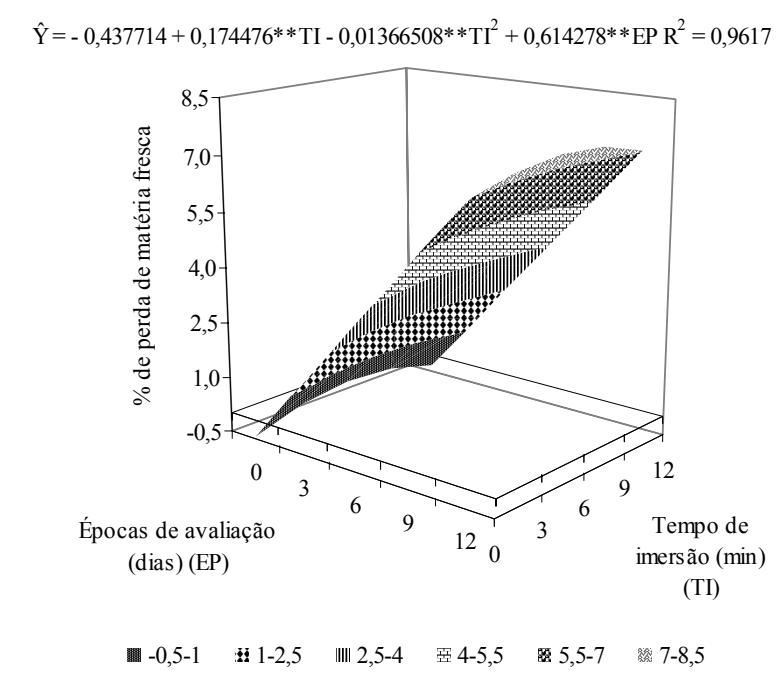

** Significativo a $1 \%$ de probabilidade, pelo teste " $\mathrm{t}$ "

Figura 1 - Estimativa da perda de matéria fresca de banana 'Prata' tratada por hidrotermia em função do tempo de imersão (TI) e das épocas de avaliação (EP).

O controle apresentou perdas diárias menores que os demais tratamentos, indicando que, no caso de banana 'Prata', a hidrotermia determina o aumento de perda de matéria fresca ao longo dos dias de avaliação. Na literatura não há referência a estudo similar. No entanto, Finger et al. (1995) observaram que perdas de peso de bananas superiores a $5 \%$ ocasionaram aumentos de 70 e $50 \%$ na taxa respiratória e na produção de etileno, respectivamente, acompanhada de decréscimo da altura 
do pico climatérico, quando comparadas a frutos com perdas de apenas $0,5 \%$.

A produção de $\mathrm{CO}_{2}$, medida uma hora após o tratamento hidrotérmico a $56^{\circ} \mathrm{C}$, foi distinta para os diferentes tempos de imersão estudados (Figura 2A). Frutos tratados por 12 minutos apresentaram taxa respiratória aproximadamente quatro vezes maior que a do controle. A partir da segunda hora de avaliação, os frutos de todos os tratamentos apresentaram taxa respiratória semelhante àquela exibida pelos frutos-controle.

Após as primeiras 24 horas, observou-se que os frutos do tratamento-controle iniciaram uma ascensão climatérica, que culminou no pico no oitavo dia após o tratamento (Figura 2B). As imersões por 3 e 6 minutos causaram retardamento no início da ascensão para o sexto dia. Imersões a 9 e 12 minutos provocaram a supressão dessa ascensão, permanecendo a taxa respiratória estabilizada nos níveis basais de aproximadamente $30 \mathrm{mg}$ $\mathrm{CO}_{2} \cdot \mathrm{kg}^{-1} \cdot \mathrm{h}^{-1}$ (Figura 2B). Nos frutos tratados a $53{ }^{\circ} \mathrm{C}$, independentemente do tempo de imersão, a ascensão climatérica não foi prejudicada (dados não apresentados).

Considerando que os tratamentos a $56^{\circ} \mathrm{C}$ por 9 e 12 minutos causaram externamente escaldaduras e retardamento do desverdecimento, além da supressão da ascensão climatérica, é possível que as temperaturas no interior da polpa tenham atingido um nível crítico para certos complexos enzimáticos envolvidos nos amadurecimentos interno e externo, entre eles o aparato enzimático responsável pela biossíntese e, ou percepção do etileno nos frutos.

Embora os binômios envolvendo as temperaturas de 53 e $56^{\circ} \mathrm{C}$ e os maiores tempos de exposição tenham causado danos ao padrão climatérico dos frutos, como discutido anteriormente, eles não interferiram, de modo significativo, no extravasamento de solutos das células das cascas (Figura 3), o que é um indicativo de que esses tratamentos não alteraram a composição e a permeabilidade de membrana dessas células.

A perda de integridade das membranas e o aumento do extravasamento de eletrólitos são, normalmente, consequências do tratamento térmico (PAULL \& CHEN, 2000), contudo, é a capacidade do tecido de manter a fluidez da membrana diante do estresse, que vai determinar a sua resistência às desordens fisiológicas, como o extravasamento de solutos (LURIE et al., 1995). No presente estudo parece ter havido a recuperação da condição normal dos frutos ao longo dos dias de armazenamento, não evidenciando efeito da temperatura e do tempo de imersão sobre essa variável.

À medida que aumentou a temperatura de imersão (T), houve tendência de retardamento do amaciamento natural dos frutos. Contudo, à medida que aumentou o tempo de armazenamento (EP), essa variável apresentou comportamento quadrático, com mínimo em torno de 80 kPa próximo ao nono dia de avaliação (Figura 4).

Bananas 'Santa Catarina Prata' e 'Dwarf Cavendish' expostas a $55^{\circ} \mathrm{C}$ por 20 minutos ou mais, não amoleceram (REYES et al., 1998). Frutos desses mesmos cultivares submetidos a temperaturas superiores a $50{ }^{\circ} \mathrm{C}$ por 15 minutos apresentaram danos ao processo de amadurecimento natural da polpa (DOMINGUES et al., 1998). Segundo Lurie (1998), a exposição de frutas ao aquecimento leva ao amaciamento mais lento, por causa da diminuição da síntese de enzimas hidrolíticas de parede celular, a exemplo de PG e $\beta$-galactosidase. Os resultados do presente estudo sugerem que isto deva ter ocorrido nos frutos tratados a temperaturas mais elevadas.
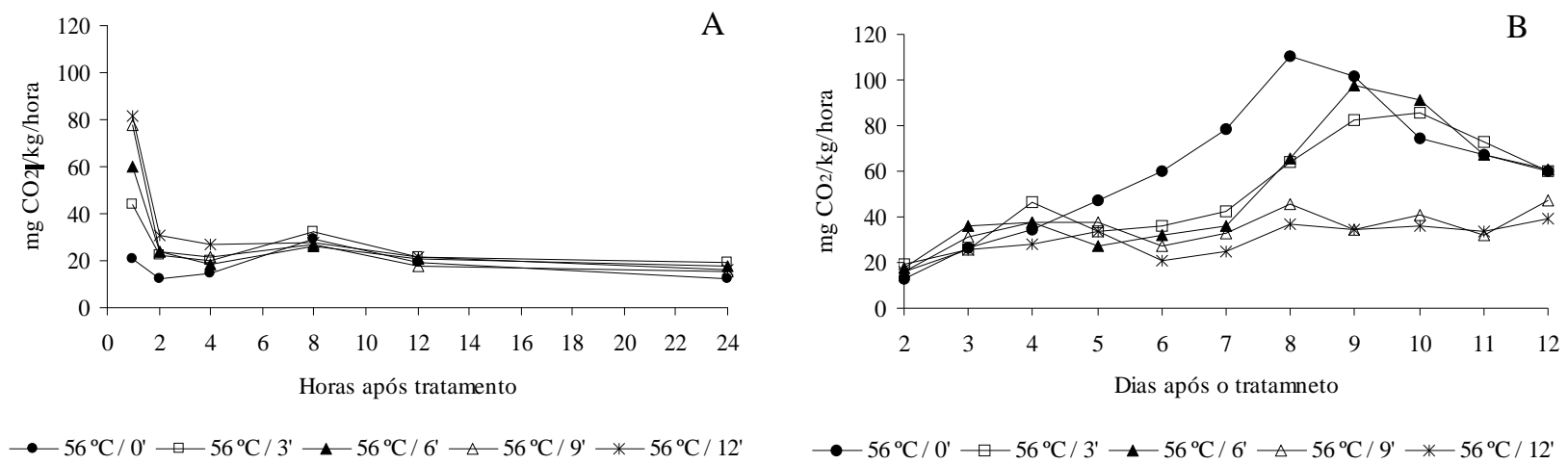

Figura 2 - Respiração de bananeira 'Prata' submetida a hidrotermia a $56^{\circ} \mathrm{C}$ por $0,3,6,9$ e 12 minutos, nas primeiras 24 $\mathrm{h}(\mathrm{A})$ e nos 12 dias subseqüentes (B) ao tratamento. 


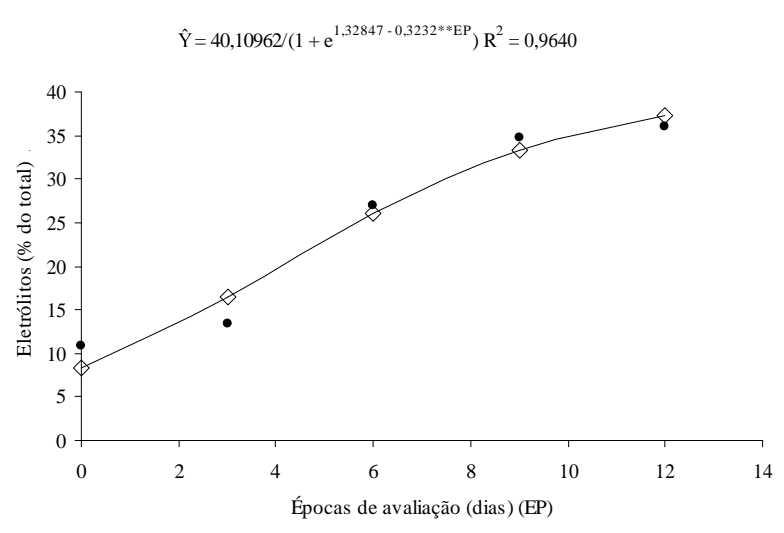

** Significativo a $1 \%$ de probabilidade, pelo teste " $\mathrm{t}$ "

Figura 3 - Extravasamento de solutos (\% de eletrólitos extravasados em relação ao total de eletrólitos celulares) da casca durante o amadurecimento de banana 'Prata' submetida à hidrotermia, em função da época de avaliação (EP).

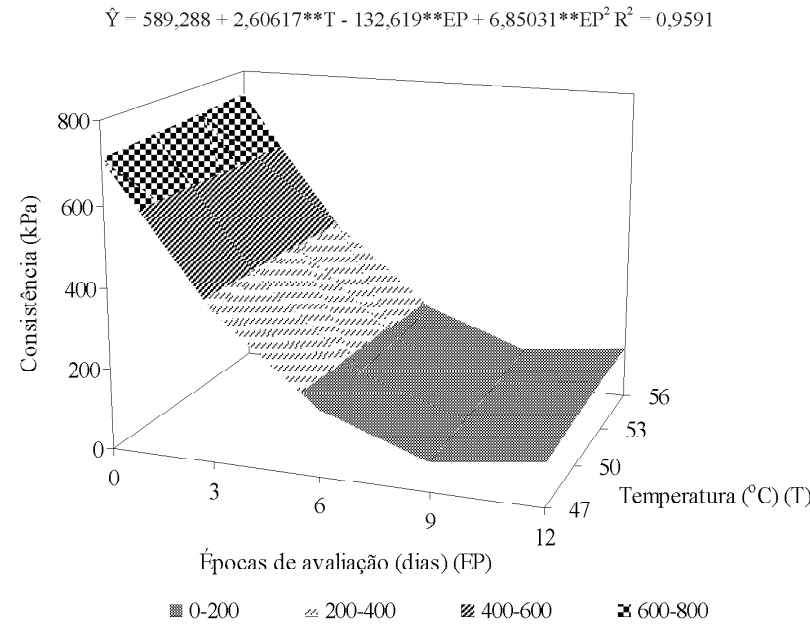

** Significativo a $1 \%$ de probabilidade, pelo teste " $\mathrm{t}$ "

Figura 4 -Estimativa do amaciamento da polpa de banana 'Prata' tratada por hidrotermia em função da temperatura de tratamento (T) e das épocas de avaliação (EP).

A acidez titulável aumentou até atingir o máximo de $0,72 \mathrm{~g}$ de ácido málico. $100 \mathrm{~g}$ de polpa ${ }^{-1}$, que ocorreu no sexto dia de avaliação (Figura 5), concomitantemente à elevação da taxa respiratória, comportamento semelhante ao encontrado por Salomão (1995) em banana 'Mysore'. Normalmente, as reduções nos conteúdos de ácidos orgânicos durante as etapas finais do amadurecimento dos frutos estão associadas aos processos de respiração e, ou conversão em açúcares (WILLS et al., 1998).
A temperatura da polpa elevou-se linearmente, tanto em função do aumento da temperatura da água quanto do incremento do tempo de imersão (Figura 6). Aos 9 minutos, as polpas dos frutos atingiram temperaturas internas de aproximadamente $37,40,42$ e 45 ${ }^{\circ} \mathrm{C}$, com as temperaturas da água de $47,50,53$ e $56^{\circ} \mathrm{C}$, respectivamente. Aos 12 minutos, as temperaturas internas subiram para $43,45,48$ e $50^{\circ} \mathrm{C}$, respectivamente. Padrão similar foi encontrado por Moraes (1999).

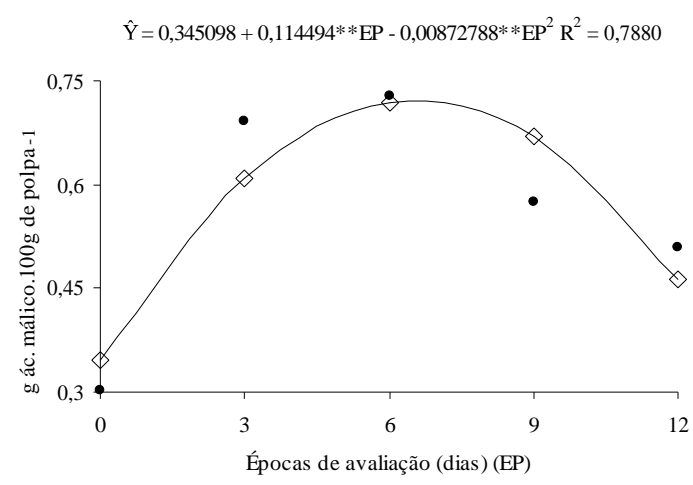

** Significativo a $1 \%$ de probabilidade, pelo teste " $\mathrm{t}$ "

Figura 5 - Estimativa da acidez titulável da polpa de banana 'Prata' submetida à hidrotermia, em função dos dias após o tratamento (EP).

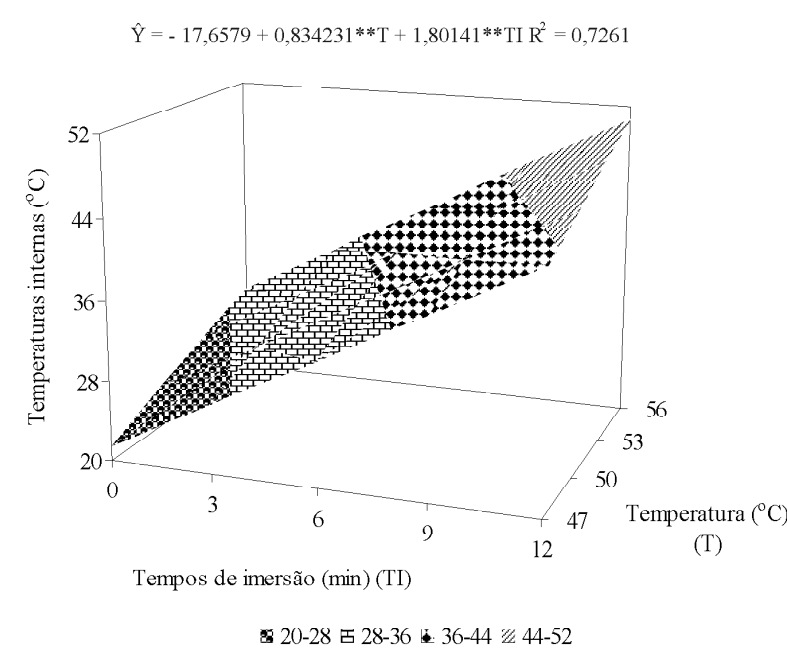

** Significativo a $1 \%$ de probabilidade, pelo teste " $\mathrm{t}$ "

Figura 6 - Estimativa da temperatura no centro da polpa de banana 'Prata' durante a hidrotermia, em função da temperatura da água de tratamento $(\mathrm{T})$ e do tempo de imersão (TI). 
Por sua vez, os tempos de retorno da temperatura da polpa aos níveis basais foram demasiadamente longos, chegando a aproximadamente 30 minutos para o binômio $56{ }^{\circ} \mathrm{C}$ por 12 minutos de imersão (Figura 7). Com isso, evidenciou-se que os dois (2) minutos de imersão em água à temperatura ambiente utilizados neste trabalho não foram suficientes para resfriar a polpa até o equilíbrio com a temperatura ambiente de modo rápido e seguro.

O fato de o tempo destinado ao resfriamento dos frutos não ter sido suficiente para retorná-los aos valores basais de temperatura pode ter influenciado o surgimento de danos por escaldaduras e falhas no padrão climatérico dos frutos.

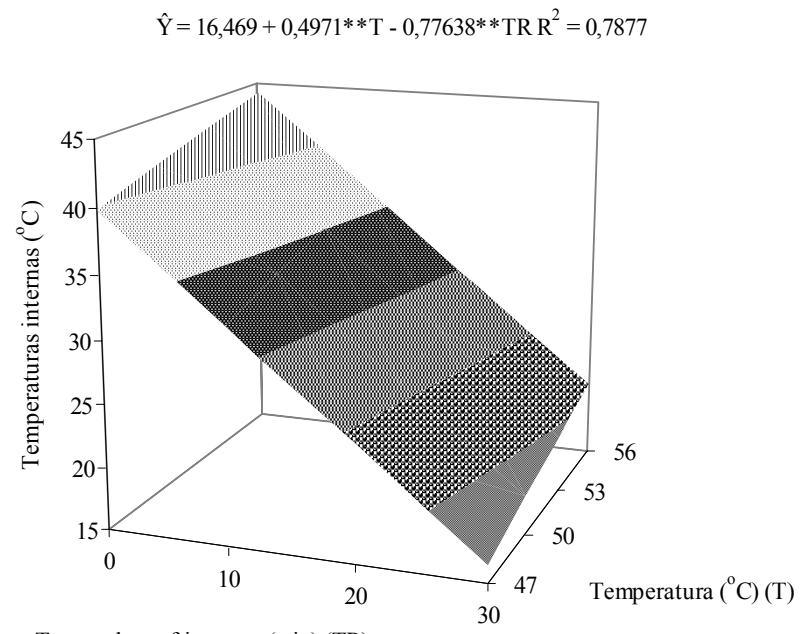

Tempo de resfriamento $(\mathrm{min})(\mathrm{TR})$

|-15-20 20-25 25-30 篮 30-35 : $35-40$ |ㅔ 40-45

** Significativo a $1 \%$ de probabilidade, pelo teste " $\mathrm{t}$ "

Figura 7 - Estimativa de temperaturas no centro da polpa de banana 'Prata' durante o resfriamento por imersão em água à temperatura de $20^{\circ} \mathrm{C}$, em função da temperatura da água de tratamento $(\mathrm{T})$ e do tempo de resfriamento (TR) min.

Observou-se que os tratamentos a $50{ }^{\circ} \mathrm{C}$ por 6 minutos e 12 minutos, $53{ }^{\circ} \mathrm{C}$ por 9 minutos e $56^{\circ} \mathrm{C}$ por 3 minutos foram os que melhor controlaram as podridões até o $12^{\circ}$ dia de armazenamento, sem causar escaldadura aos frutos (dados não mostrados). Pelos dados apresentados neste trabalho, verifica-se que aquelas combinações de tratamentos também não tiveram efeitos negativos sobre o amadurecimento da banana 'Prata' e, portanto, podem ser utilizados no controle de podridões pós-colheita.

\section{CONCLUSÕES}

Bananas 'Prata' tratadas em água à temperatura de $56^{\circ} \mathrm{C}$ durante 9 e 12 minutos não apresentaram a ascensão climatérica da respiração, prejudicando seu amadurecimento.

Bananas 'Prata' podem ser tratadas em água a temperaturas de $50^{\circ} \mathrm{C}$ por 6 e 12 minutos, $53^{\circ} \mathrm{C}$ por 9 minutos e $56^{\circ} \mathrm{C}$ por 3 minutos, sem afetar o seu amadurecimento, e permitindo qualidade pós-colheita adequada.

\section{REFERÊNCIAS BIBLIOGRÁFICAS}

BURDEN, O. J. Reduction of banana anthracnose following hot-water treatment of the green fruit. Queensland Department of Primary Industries, [S.1.], v. 25, p. 135-144, 1968.

DADZIE, B. K.; ORCHARD, J. E. Evaluación rutinaria postcosecha de híbridos de bananos y plátanos: criterios y métodos. Roma: IPGRI; Montpelier: INIBAP, 1996. 63 p. (Guias técnicas Inibap, 2).

DOMINGUES, A. M.; CABRERA, J. J. L.; GARCÍA, P. M. Effects of hot water treatments on postharvest quality and ethylene synthesis of bananas. Acta horticulturae, Leuven, n. 490, p. $529-535,1998$.

FINGER, L. F.; PUSCHMANN, R.; BARROS, R. S. Effects of water loss on respiration, ethylene production and ripening of banana fruit. Revista Brasileira de Fisiologia Vegetal, Curitiba, v. 7, n. 1, p. 115-118, 1995.

LURIE, S. Postharvest heat treatments. Postharvest Biology and Technology, Amsterdam, v. 14, p. 257-269, 1998.

LURIE, S.; OTHMAN, S.; BOROCHOV, A. Effects of heat treatment on plasma membrane of apple fruit. Postharvest Biology and Technology, Amsterdam, v. 5, p. 29-38, 1995.

MORAES, W. da S. Integração de métodos de controle de podridões em pós-colheita da banana 'PrataAnã'(AAB). 1999. 84 f. Tese (Doutorado em Fitopatologia) Universidade Federal de Viçosa, Viçosa, 1999.

PAULL, R. E.; CHEN, N. J. Heat treatment and fruit ripening. Postharvest Biology and Technology, Amsterdam, v. 21, p. 21-37, 2000 .

REYES, M. E. Q.; NISHIJIMA, W.; PALL, R. E. Control of crown rot in 'Santa Catarina Prata' and 'Williams' banana with hot water treatments. Postharvest Biology and Technology, Amsterdam, v. 14, p. 71-75, 1998. 
SALOMÃO, L. C. C. Efeitos do envoltório plástico no desenvolvimento e na maturação pós-colheita de frutos de banana (Musa AAB) 'Mysore'. 1995. $104 \mathrm{f}$. Tese (Doutorado em Fitotecnia) - Universidade Federal de Viçosa, Viçosa, 1995.

SEREK, M.; TAMARI, G.; SISLER, E. C.; BOROCHOV, A. Inhibition of ethylene-induced cellular senescence symptoms by 1-methylcyclopropene, a new inhibitor of ethylene action. Physiologia Plantarum, Copenhagen, v. 94, p. 229-232, 1995.

WILLS, R.; MCGLASSON, B.; GRAHAM, D.; JOYCE, D. Postharvest: an introduction to the physiology and handling of fruits, vegetables and ornamentals. 4. ed. Wallingford: CABI, 1998. 262 p. 